\title{
EFFECT OF ITRACONAZOLE ON THE LIVER OF ADULT MALE ALBINO RAT AND THE POSSIBLE PROTECTIVE ROLE OF COENZYME Q10 (HISTOLOGICAL, IMMUNOHISTOCHEMICAL AND BIOCHEMICAL STUDY)
}

\author{
By \\ Hala H. M. Mossalam ${ }^{1 *}$ and Asmaa Fathy Yousuf ${ }^{2}$ \\ ${ }^{1}$ Department of Anatomy and Embryology, Faculty of Medicine for Girls, Al-Azhar \\ University \\ ${ }^{2}$ Department of Physiology, Faculty of Medicine for Girls, Al-Azhar University \\ E-mail: halahamed1000@gmail.com
}

\begin{abstract}
Background: The efficacy and therapeutic benefit of itraconazole as antifungal medication can be clinically limited by the incidence of hepatotoxicity.

Objective: Detection of the effect of itraconazole administration on the histological structure and function of the liver in adult male rat and its amelioration by Coenzyme Q 10 (COQ 10) use.

Materials and Methods: Forty adult male albino rats were used and divided into four equal groups. Group I: Control group, Group II received Coenzyme Q10 $(10 \mathrm{mg} / \mathrm{Kg} /$ day $)$ for four weeks, Group III were treated orally with itraconazole $(100 \mathrm{mg} / \mathrm{kg} /$ day $)$ for four weeks and Group IV pre-treated with Coenzyme Q10 orally $(10 \mathrm{mg} / \mathrm{Kg} /$ day $) 2$ hours prior to itraconazole $(100 \mathrm{mg} / \mathrm{kg} / \mathrm{day})$ for four weeks. After the end of the experiment, the rats were sacrificed under anesthesia and blood samples were collected for assessment of liver function tests (ALT, AST, and ALP). Liver tissue specimens were collected for histopathological examination and assessment of liver tissue levels of MDA, SOD, CAT, and GSH.

Results: Histopathological examination using light and electron microscope showed that itraconazole induced marked distortion of liver parenchyma, hepatic congestion with vacuolar degeneration of hepatocytes which associated with significant increase in AST, ALT, and ALP as compared to control group There was also a significant increase in liver malondialdehyde (MDA) level, with significant decrease in liver superoxide dismutase (SOD) catalase (CAT) and glutathione peroxidase (GSH). Pre-treatment with CoQ10 reduced itraconazole hepatic affection with preservation of histological picture of the liver tissues, liver function parameters and oxidative stress biomarkers.
\end{abstract}

Conclusion: COQ 10 reduced itraconazole-induced hepatotoxicity in adult male albino rats.

Key Words: antioxidant, itraconazole, liver, rat, toxicity.

\section{INTRODUCTION}

The azole antifungals are synthetic compounds that prevent the synthesis of ergosterol in the fungal cell membrane. Itraconazole is lipophilic antifungal agents used in the treatment of infections caused by various pathogenic yeast and fungi (Bellmann and Smuszkiewicz, 2017). Itraconazole-induced liver injury is not rare. However, hepatocellular damage has been described in cases of acute liver failure with antifungal agent use (Tverdek 
et al; 2016). Unfortunately, long-term use of itraconazole about $31.5 \%$ of patients developed hepatotoxicity. Treatment cessation due to itraconazole -induced hepatic injury was detected in $1.6 \%$ of patients (Girois, et al., 2006). Few drugs might be complicated by hepatotoxicity due to various mechanisms like changes in liver mitochondrial functions, oxidative stress, and alteration of expression of liver genes (Russmann et al., 2009). Coenzyme Q10 (CoQ10), or ubiquinone, is natural fat-soluble, vitamin-like antioxidants can be formed endogenously or provided via food. It is detected in the biological membranes of cellular organelles, such as lysosomes and peroxisomes, and is mainly located in the mitochondrial membrane as part of the electron transport chain, which is responsible for adenosine triphosphate (ATP) synthesis (Da Silva et al., 2013). CoQ10 biosynthesis occurs in the mitochondrial membrane of vital organs with high-energy turnover such as brain, heart, kidney, liver, and muscle (Acosta et al., 2016).

The present work aimed to demonstrate the effect of itraconazole on the histological structure and function of the liver in male albino rats and the possible protective role of CoQ10. Which may have clinical application in cases of hepatic affection associated with long term itraconazole use.

\section{MATERIALS AND METHODS}

\section{Drugs:}

Itraconazole was purchased as capsules with a trade name Sporanox capsules produced by Janssen-Cilag pharmaceutica (Beerse, Belgium).
Coenzyme Q10 was purchased from the Sigma C

hemical Company, Cairo, Egypt.

\section{Animals:}

Forty adult male albino rats of a local strain weighing from $120-150 \mathrm{~g}$ were used in this study. They were housed in clean properly ventilated cages and maintained on balanced water and diet (standard diet pellets- El-Nasr-company, Abo-Zaabal - Egypt) in the animal house of Faculty of Medicine (Girls), Al- Azhar University during the period from January 2017 to January 2018. All procedures were conducted in accordance with the animal care committee of Al-Azhar University. The "Principles of laboratory animal care" were followed, as well as specific national laws where applicable. Rats were kept in metallic cages (50) $45 \times 35-5$ rats per cage) for 3 weeks for acclimzation before beginning of the experiment.

\section{Experimental Design:}

This study lasts for four weeks and the rats were divided equally into four experimental groups:

Group I: Served as a control group and received $1.0 \mathrm{ml}$ of distilled water orally.

Group II: Rats received a single morning daily dose of CoQ10 (10 mg/Kg/day) orally according to (Adil et al., 2015).

Group III: Rats received a single morning daily dose of itraconazole (100 $\mathrm{mg} / \mathrm{kg} / \mathrm{day}$ ) orally according to (Sozen et al., 2014).

Group IV: Rats pre-treated with CoQ10 (10 $\mathrm{mg} / \mathrm{kg} /$ day) 2 hours before itraconazole $\quad(100 \quad \mathrm{mg} / \mathrm{kg} /$ day $)$ administration. 
At the end of the experimental period, rats were fasted for 14 hours then subjected to diethyl ether light anesthesia and blood samples were collected from the retro-orbital plexus of veins of all rats by fine capillary heparinized tubes (Simmons and Brick, 1970). Samples were left to clot at room temperature then centrifuged at $1500 \mathrm{rpm}$ for $10 \mathrm{~min}$ for serum preparation for estimation of serum levels of AST, ALT, and ALP. Animals were then sacrificed, and the liver was dissected, and its lobes were separated. One lobe was prepared, homogenized using an electrical homogenizer by mixing $0.5 \mathrm{~g}$ of tissue with $5 \mathrm{ml}$ phosphate buffer saline at $4{ }^{\circ} \mathrm{C}$. The homogenates were centrifuged at $3000 \mathrm{rpm}$ for $15 \mathrm{~min}$. The collected supernatant was conserved at $20{ }^{\circ} \mathrm{C}$ until further use for assessment of oxidative stress markers. The other was fixed for histopathological studies using both light and electron microscopes.

\section{Histological and immunohistochemical study:}

Liver specimens were fixed in $10 \%$ formalin saline for 24 hours, washed, dehydrated, cleared, and embedded in paraffin. Then, $5 \mu \mathrm{m}$ sections for hematoxylin and eosin (H\&E) staining (Wilson and Gamble, 2002), and PCNA (proliferating cell nuclear antigen) immunohistochemical staining. Other specimens were fixed in $2 \%$ glutaraldehyde and then processed for transmission electron microscopic examination (Glauret and Lewis, 1998). Semithin sections $(1 \mu \mathrm{m}$ thick) were cut, stained with toluidine blue, and examined by light microscope to select the area for ultrathin cutting. The ultrathin sections were mounted on copper grids, stained with uranyl acetate and lead citrate, then examined and photographed by Joel Jem transmission electron microscope-Faculty of science, Ain Shams University, Cairo, Egypt.

\section{Morphometric study:}

All PCNA stained sections were examined by image analyzer computer system in Pathology Department, Faculty of Dentist, Cairo University. It was used to obtain the morphometric data in this study using the software Leica Qwin500 (Leica Microsystems, Switzerland). Measurements were taken in five randomly selected nonoverlapping fields per slide from all studied groups. Mean area percentage of PCNA-immunopositive hepatocytes was used as a marker of hepatocyte regeneration.

\section{Biochemical measurements:}

1. Assessment of liver function tests: Alanine aminotransferase (ALT) IU/L, aspartate aminotransferase (AST) IU/L, and alkaline phosphatase (ALP) IU/L were determined as described by Ochei and Kolhatkar (2008).

2. Assessment of oxidative stress markers: Assessment of malondialdehyde (MDA) level in liver homogenate was estimated according to the method of Ohkawa et al. (1979). SOD activity was determined according to the method of Mark Lund (1985). CAT activity was estimated using commercial kits (Biodiagnostic, Egypt), and GSH was evaluated by the methods of Ellman (1959). The biochemical measurements were carried out at Biochemistry Department, Faculty of Medicine, Cairo University. 
HALA H. M. MOSSALAM et al.,

Statistical analysis: The results were statistically analyzed using (SPSS, 12) statistic package and (Expressed as means \pm SD). Statistical significance was determined by using one-way ANOVA followed by a Tuckey post-Hoc test for multiple comparisons. $\mathrm{P}$ value $\leq 0.05$ was considered statistically significant.

\section{RESULTS}

1. Light microscopic findings:

I. Group I (Control group) revealed the normal classic hexagonal hepatic lobules with radially arranged plates of hepatocytes radiating from the central veins to the periphery of the lobule. The hepatocytes were polyhedral in shape with acidophilic cytoplasm containing basophilic granules and vesicular rounded nuclei. Some hepatocytes were binucleated. The hepatocytes were separated from each other by irregular narrow blood sinusoids, which were lined with flattened endothelial cells and bulging Von Kupffer cells (Fig. 1a).

II. Group II (CoQ10 treated group) showed normal liver architecture, normal appearance of central veins with radiating cords of hepatocytes separated by blood sinusoids with no histo-pathological alterations. The hepatocytes were polyhedral in shape with acidophilic cytoplasm and central vesicular nuclei (Fig. 1b).

III.Group III (Itraconazole treated group) showed marked distortion of liver parenchyma with disturbed radial arrangement of the hepatocytes with congestion and dilation of the central vein. The hepatocytes appeared enlarged with cytoplasmic vacuolations with either hyperchromatic or pyknotic nuclei. Some hepatocytes appeared shrunken with nuclear pyknosis. Hepatic sinusoids were seen obliterated in some areas and appeared dilated and congested in other areas with inflammatory cells infiltration (Fig.1c).

IV. Group IV (Itraconazole and CoQ10 treated group) showed restoration of hepatic architecture with minimal dilation and congestion of central veins and hepatic sinusoids. The hepatocytes were organized in branching and anastomosing cords with acidophilic cytoplasm and vesicular nuclei except for the presence of few vacuolated hepatocytes (Fig. 1d). 


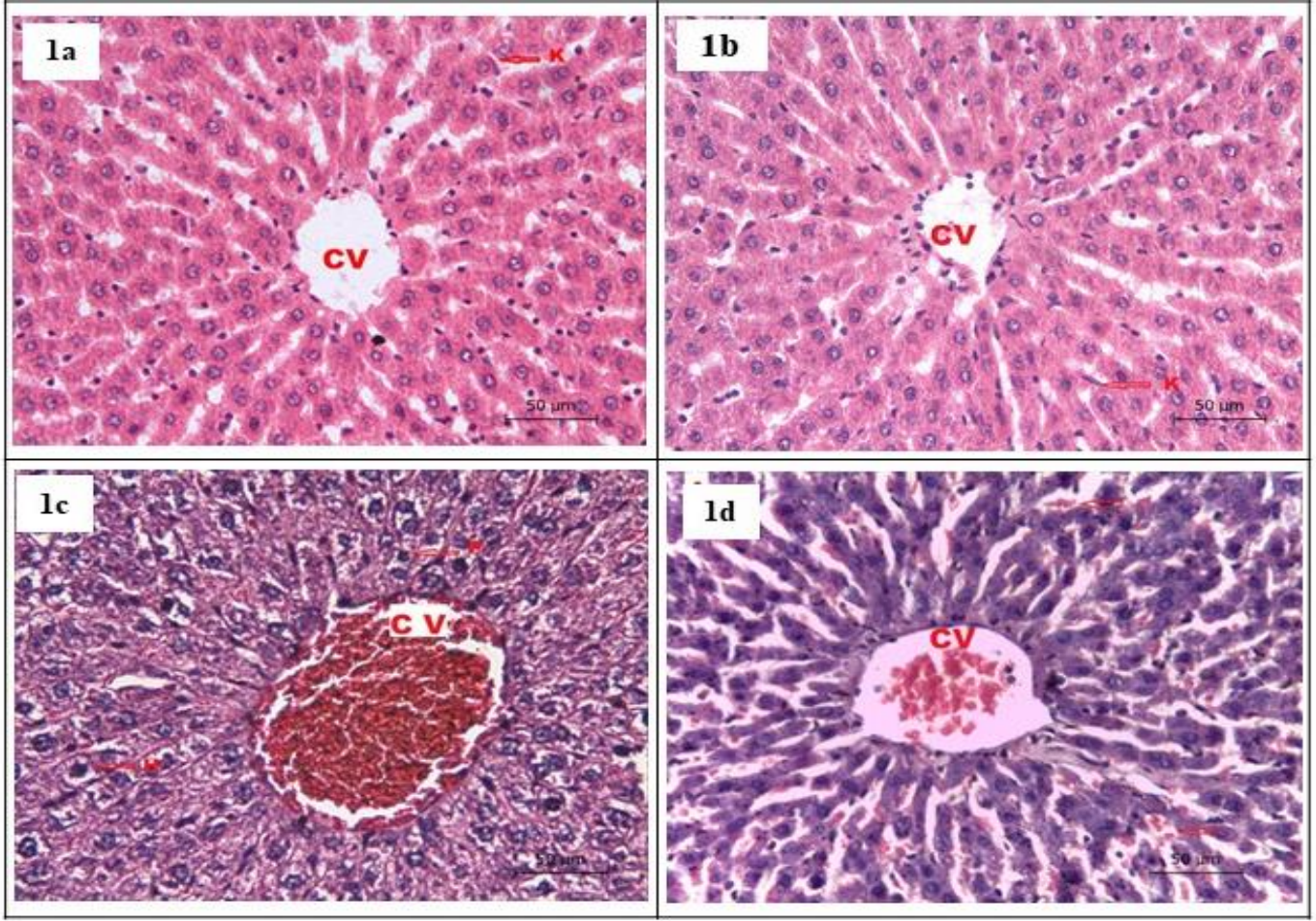

Fig.(1a): A photomicrograph of transverse sections from the rat liver of group I, showed cords of hepatocytes radiating from the central vein $(\mathrm{CV})$ and separated by irregular narrow blood sinusoids lined with endothelial cells and Kupffer cells (K-arrow). (H \& E X 400)

Fig.(1b): A photomicrograph of transverse sections from the rat liver of group II, showed central vein (CV) with radiating hepatic cords separated by blood sinusoids which lined by endothelial cells and Kupffer cells (K-arrow). (H \& E X 400)

Fig.(1c): A photomicrograph of transverse sections from the rat liver of group III, showed dilated congested central vein $(\mathrm{CV})$ with cytoplasmic vacuolation of hepatocytes with either hyperchromatic $(\mathrm{H})$ or pyknotic nuclei $(\mathrm{P})$. (H \& E X 400)

Fig.(1d): A photomicrograph of transverse sections from the rat liver of group IV, showed minimal dilatation and congested central vein (CV) and congested hepatic sinusoids (arrows). (H \& E X 400)

2. Electron microscopy findings:

I. Group I (Control group) revealed normal hepatic ultrastructure. In each hepatocyte the nucleus appeared rounded with prominent nucleoli and surrounded by regular rough endoplasmic reticulum. The cytoplasm mainly filled with multiple cytoplasmic cell organelles as mitochondria, rough endoplasmic reticulum, peroxisomes, smooth endoplasmic reticulum, glycogen granules and few lipid droplets. The glycogen granules appeared as electron dense aggregates in close relation to smooth endoplasmic reticulum (Figs. 2a, 2b).

II. Group II (CoQ10 treated group): The hepatocyte showed the normal ultrastructural appearance. The 
hepatocytes had euchromatic nuclei with a prominent nucleolus. The cytoplasm showed numerous mitochondria, rough endoplasmic reticulum which surrounded the nuclei, smooth endoplasmic reticulum, and glycogen granules (Figs. 2c, 2d).

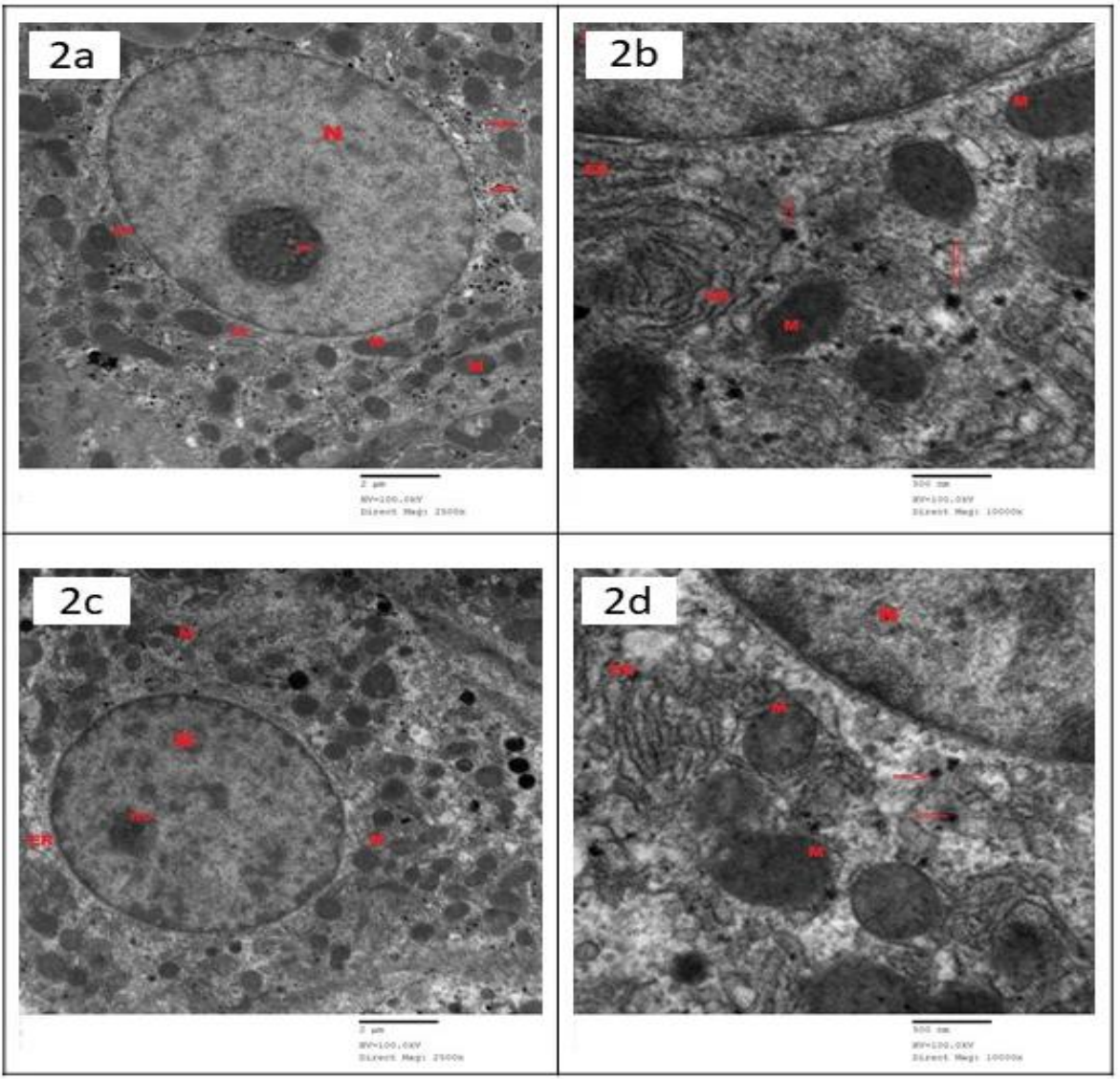

Fig. (2a): An electron micrograph from liver of group I, showed hepatocyte nuclei $(\mathrm{N})$, mitochondria $(\mathrm{M})$, regular rough endoplasmic reticulum (ER) and glycogen granules (arrows). (TEM X 2.500)

Fig. (2b): An electron micrograph from liver of group I, showed numerous mitochondria (M), regular rough endoplasmic reticulum (ER) and glycogen granules (arrows). (TEM X 10000)

Fig. (2c): An electron micrograph from liver of group II, showed hepatocyte euchromatic nuclei $(\mathrm{N})$ rough endoplasmic reticulum (ER), numerous mitochondria $(\mathrm{M})$. (TEM X 2.500)

Fig. (2d): An electron micrograph from liver of group II, hepatocyte euchromatic nuclei $(\mathrm{N})$, rough endoplasmic reticulum (ER), numerous mitochondria $(\mathrm{M})$ and glycogen granules (arrows). (TEM X 10000)

III.Group III (Itraconazole treated group): The hepatocyte had indented nuclei with irregular nuclear membrane. The cytoplasm showed accumulation of numerous irregular electron lucent lipid vacuoles of variable shapes and sizes. In addition, the cytoplasm contained swollen mitochondria with destroyed cristae, fragmented rough endoplasmic 
reticulum and little or depleted glycogen granules (Figs. 3a, 3b).

IV. Group IV (Itraconazole and CoQ10 treated group): There was amelioration and reduction in the structural impairment induced by itraconazole as hepatocyte appeared as the control. The nucleus appeared euchromatic rounded with prominent nucleolus. The cytoplasmic organelles were nearly normal except for few lipid vacuoles and slightly enlarged mitochondria (Figs. 3c, 3d).

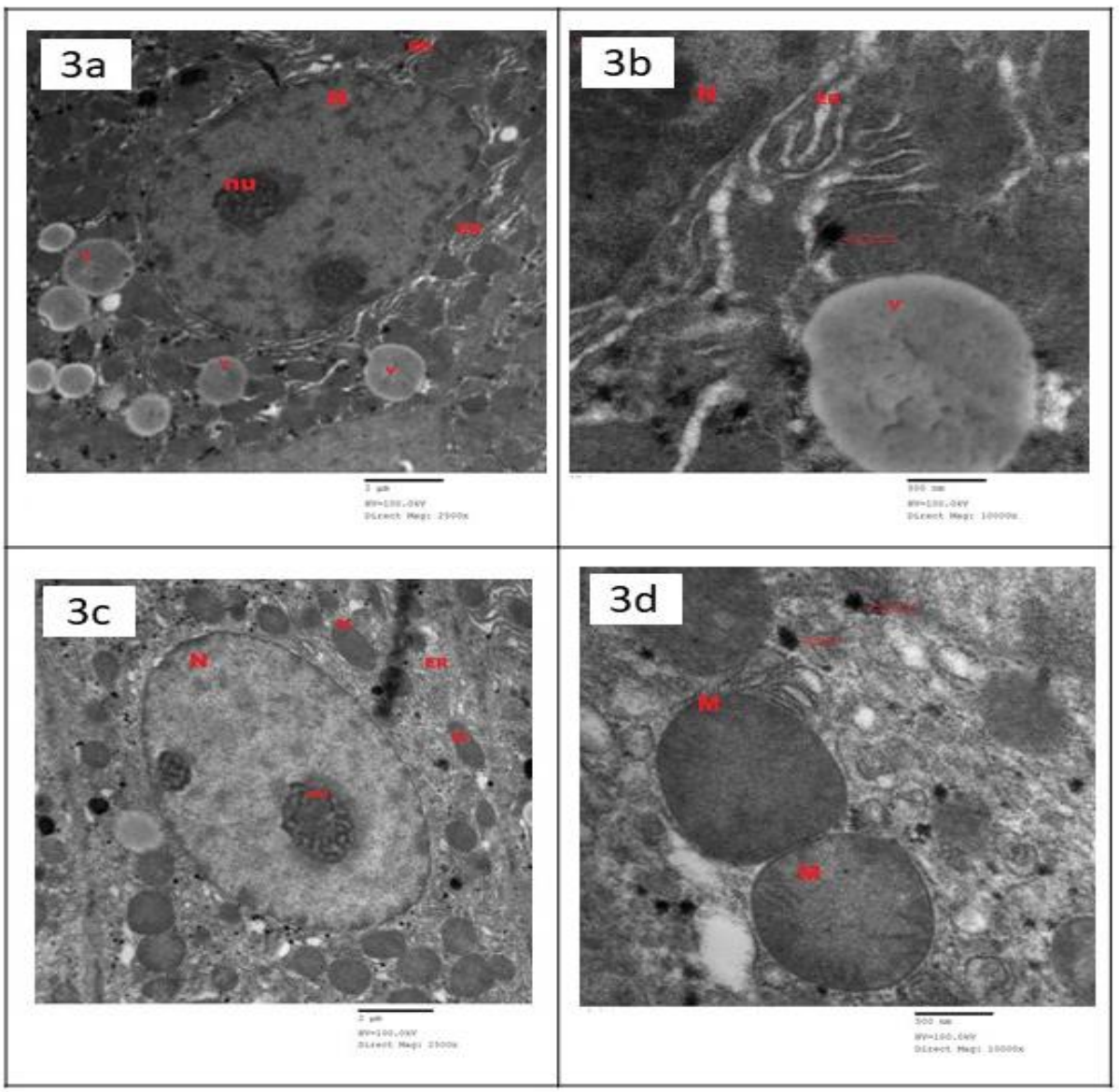

Fig. (3a): An electron micrograph from liver of group III, showed hepatocyte indented nuclei $(\mathrm{N})$, nucleoli $(\mathrm{nu})$, lipid droplets $(\mathrm{V})$ rough endoplasmic reticulum $(\mathrm{ER})$. (TEM X 2.500)

Fig. (3b): An electron micrograph from liver of group III, showed hepatocyte indented nuclei (N) lipid vacuoles (V), rough endoplasmic reticulum (ER) and glycogen granules (arrow). (TEM X 10000)

Fig. (3c): An electron micrograph from liver of group IV, showed hepatocyte with euchromatic nucleus $(\mathrm{N})$ nucleoli (nu), rough endoplasmic reticulum (ER) and mitochondria (M). (TEM X 2.500)

Fig. (3d): An electron micrograph from liver of group IV, showed slightly enlarged mitochondria (M) and glycogen granules (arrows). (TEM X 10000) 
3. Immunohistochemical study:

Examination of PCNA immuno-stained sections showed few faint PCNA positive hepatocytes which expressed as brown nuclear staining were seen in the control group (Fig. 4a). In group II, there were few PCNA positive hepatocytes as the control (Fig. 4b). In group III, showed increase in PCNA positive hepatocytes (Fig. 4c). In group IV, showed decrease in PCNA positive hepatocytes (Fig. 4d).

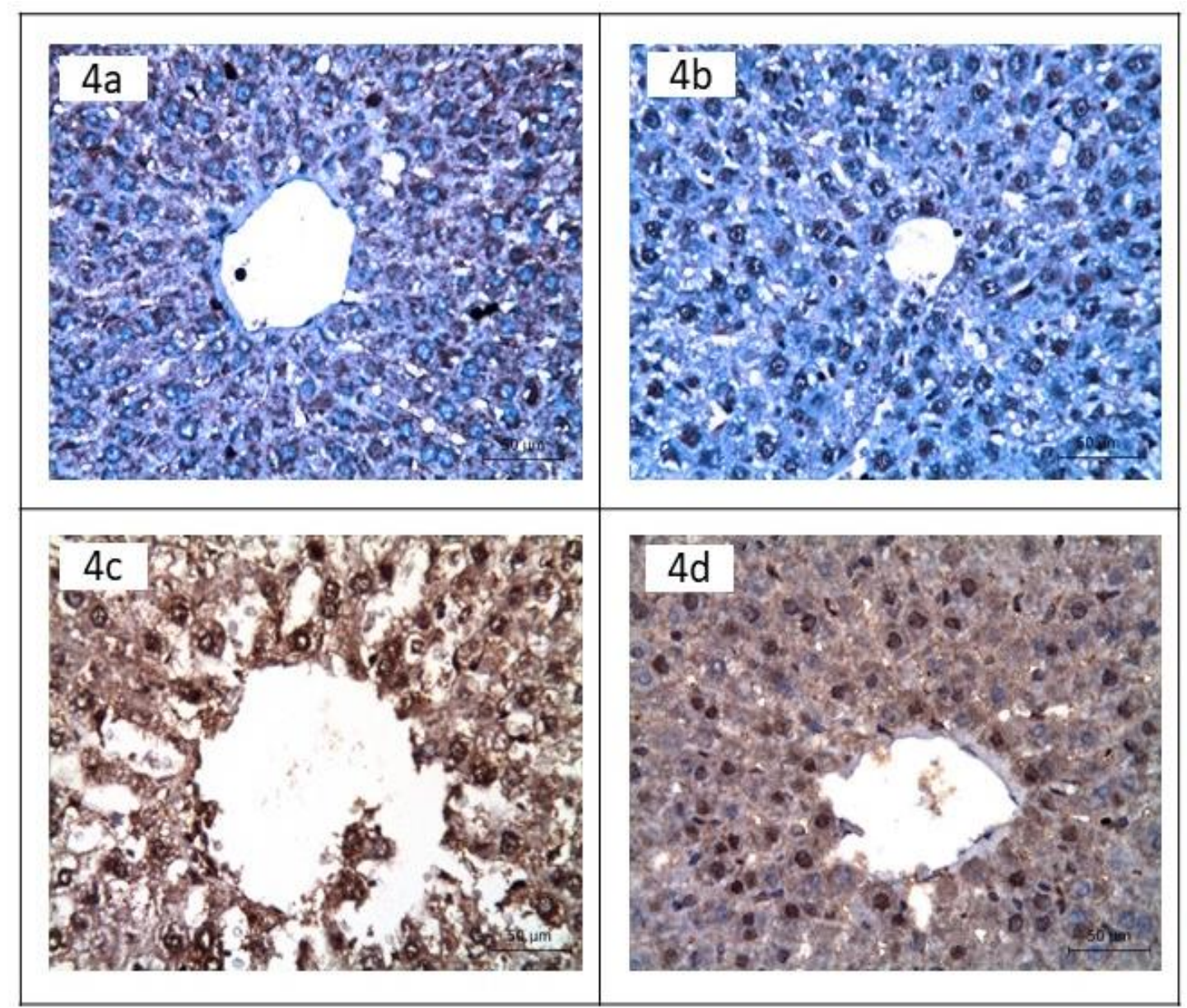

Fig. (4a): A photomicrograph of transverse sections from the rat liver of group I, showed few faint PCNA positive hepatocytes. (PCNA stain X 400)

Fig. (4b): A photomicrograph of transverse sections from the rat liver of group II, showed few PCNA positive hepatocytes. (PCNA stain X 400)

Fig. (4c): A photomicrograph of transverse sections from the rat liver of group III, showed increase in PCNA positive hepatocytes. (PCNA stain X 400)

Fig. (4d): A photomicrograph of transverse sections from the rat liver of group IV, showed decrease in PCNA positive hepatocytes. (PCNA stain X 400)

Morphometric studies:

The morphometric studies of the mean area percentage positive cells for PCNA immunostaining for studied experimental groups was represented in histogram (1) which revealed significant decrease in PCNA area percentage ( $\mathrm{p}$ value $<0.05$ ) in group IV when compared with group III.

[Histogram (I)] 


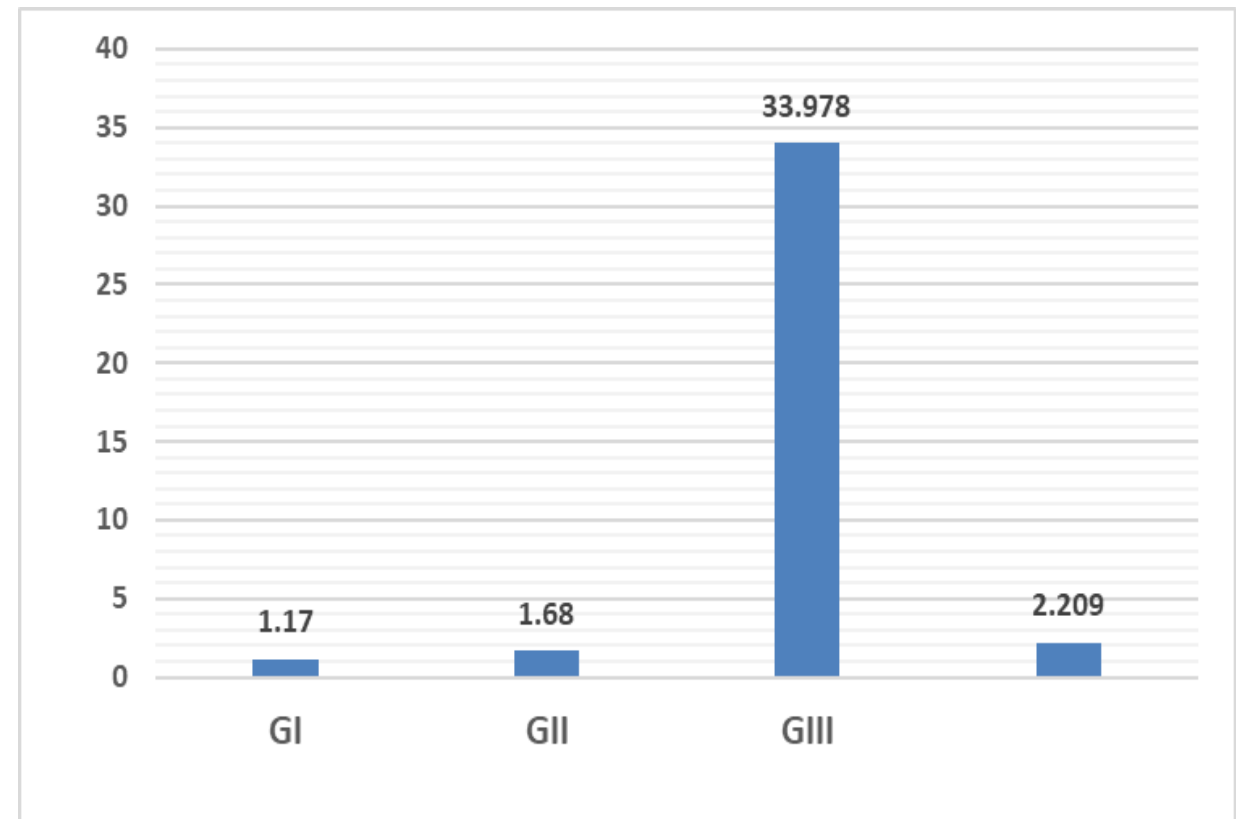

Histogram (I): Showing the mean area \% of PCNA reaction in all experimental groups

\section{Biochemical results}

1. Assessment of liver function tests: Biochemical results revealed insignificant differences in the levels of liver enzymes ALT, AST ALP between group I and group II. In group III, there was significant increase in liver enzymes ALT, AST, and ALP, if compared to group I and group II. Liver enzymes were significantly decreased in group VI when compared to group III (Table1).

2. Assessment of tissue oxidative stress markers revealed insignificant differences in the levels tissue MDA, tissue SOD, CAT and GSH between group I and group II. Group III showed significant disturbance with increased tissue MDA, decreased tissue SOD, CAT and GSH when compared to group I and group II. In group IV, when CoQ10 was administered with itraconazole, it ameliorated the apparent liver functions deterioration and oxidative stress. In addition, there was a significant decrease in tissue MDA as well as the significant increase in tissue SOD, CAT and GSH in group VI when compared to group III (Table 1). 
HALA H. M. MOSSALAM et al.,

Table (1): Levels of ALT, AST, ALP, tissue MDA, tissue SOD, tissue CAT, tissue GSH in all studied groups

\begin{tabular}{|c|c|c|c|c|c|c|}
\hline \multirow{2}{*}{ Groups } & Group (I) & $\begin{array}{c}\text { Group } \\
\text { (II) }\end{array}$ & Group (III) & $\begin{array}{c}\text { treated Group } \\
\text { (IV) }\end{array}$ & \multicolumn{2}{|c|}{ ANOVA } \\
\cline { 2 - 7 } & Mean \pm S.D. & Mean \pm S.D. & Mean \pm S.D. & Mean \pm S.D. & F & $\begin{array}{c}\text { P- } \\
\text { value }\end{array}$ \\
\hline ALT (U/L) & $15.08 \pm 2.85$ & $14.68 \pm 3.19$ & $44.87^{\mathbf{a}} \pm 1.96$ & $25.03^{\mathbf{b}, \mathbf{c}} \pm 3.19$ & 8.2 & 0.002 \\
\hline AST (U/L) & $15.91 \pm 3.15$ & $16.27 \pm 3.3$ & $52.87^{\mathbf{a}} \pm 2.51$ & $31.93^{\mathbf{b}, \mathbf{c}} \pm 4.18$ & 9.7 & 0.001 \\
\hline ALP (U/L) & $115.66 \pm 2.69$ & $115.58 \pm 11.24$ & $225.5^{\mathbf{a}} \pm 3.12$ & $183.59^{\mathbf{b}, \mathbf{c}} \pm 8.79$ & 6.9 & 0.004 \\
\hline $\begin{array}{c}\text { Tissue } \\
\text { MDA (nmol/ } \\
\text { g tissue) }\end{array}$ & $25.86 \pm 2.29$ & $25.64 \pm 6.86$ & $72.34^{\mathbf{a}} \pm 9.04$ & $43.1^{\mathbf{b}, \mathbf{c} \pm 4.64}$ & 7.09 & 0.003 \\
\hline $\begin{array}{c}\text { Tissue SOD } \\
\text { (u/mg tissue) }\end{array}$ & $9.35 \pm 2.5$ & $8.77 \pm 1.004$ & $3.74^{\mathbf{a}} \pm 1.94$ & $5.83^{\mathbf{b}, \mathbf{c}} \pm 1.9$ & $\mathbf{6 . 2}$ & $\mathbf{0 . 0 0 9}$ \\
\hline $\begin{array}{c}\text { Tissue CAT } \\
\text { (u/mg } \\
\text { tissue.) }\end{array}$ & $128.41 \pm 11.24$ & $128.44 \pm 9.14$ & $62.69^{\mathbf{a}} \pm 13.48$ & $101.73^{\mathbf{b}, \mathbf{c}} \pm 7.07$ & $\mathbf{8 . 2}$ & $\mathbf{0 . 0 0 2}$ \\
\hline $\begin{array}{c}\text { Tissue GSH } \\
\text { (nmol/g } \\
\text { tissue) }\end{array}$ & $75.95 \pm 6.82$ & $79.71 \pm 4.86$ & $32.75^{\mathbf{a}} \pm 6.81$ & $55.06^{\mathbf{b}, \mathbf{c}} \pm 9.03$ & 17.06 & 0.000 \\
\hline
\end{tabular}

a, b, c: significant values compared to control, itraconazole group, CoQ 10 group respectively. Significant values when $\mathrm{P}<0.05$, using one-way ANOVA followed by Tuckey post-Hoc test.

\section{DISCUSSION}

In the current work, we demonstrated the hepatic structural alterations caused by itraconazole in rats. These alterations included marked congestion and dilation of the central vein and cytoplasmic vacuolations. These changes were documented previously by Kemeir (2014) who revealed features of liver affection and hepatocytes degeneration with cytoplasmic vacuolation with itraconazole. This finding was explained by (Hassan et al., 1988) who found vascular dilation and hepatic congestion with ketoconazole use, which might be due to direct action on the blood vessels wall or due to back pressure in the portal vein because of fatty infiltration. The observed cytoplasmic vacuoles in this study like that observed by (Sozen et al., 2014) who described hepatocyte degeneration, bile duct hyperplasia, inflammation of the portal area and apoptotic cell formation with itraconazole use. In this study vacuolation in liver cells might be lipid vacuoles associated with increased lipid peroxidation. This finding was explained by (Talwalkar et al. 1999) who mentioned that itraconazole metabolism occurs primarily in the liver so, any adverse effects are expressed primarily in the liver.

In this experiment, few faint PCNA positive nuclear reactions were seen in control group. This finding was explained by (Cheung et al., 2006) who explained that in normal conditions, the hepatocytes undergo a very low regeneration rate as they are generally quiescent and regenerate in a limited and regulated manner. However, in the current study, rats that received itraconazole PCNA positive reaction was seen in hepatocytes with significant increase in area percentage of PCNA-positive cells reflecting rapid proliferation in the 
hepatocytes. This might be explained by (Morales-Gonzalez et al., 2001) who mentioned that liver regeneration is the organized and controlled response toward tissue damage induced by drugs, trauma, toxic agents, or infections.

In the current research, light microscopic findings were confirmed by the electron microscope. Itraconazole resulted in distortion to most of intracellular organelles which represented by cytoplasmic vacuolations, mitochondrial alterations, distortion of endoplasmic reticulum and decrease of glycogen granules. This finding is supported by the work of Rafique et al. (2010) who found similar histological findings in rats treated with ketoconazole and explained that the toxic metabolites might be damage the smooth endoplasmic reticulum, mitochondria, and plasma membrane. The damage might be explained by (Rubin., 2001) who attributed this to the oxygen metabolites with deficiency of the protective enzymes from the liver following drug consumption. However, (Kumar et al., 2004) attributed this mitochondrial damage to widening of the mitochondrial permeability transition pore with loss of mitochondrial membrane potential and $\mathrm{pH}$ changes. Which resulted in failure of oxidative phosphorylation and progressive depletion of energy production (ATP) with subsequent dilatation of cytoplasmic membranous components and formation of cytoplasmic vacuolations.

The apparent deterioration in liver functions by itraconazole in this study could be attributed to oxidative stress. These findings agreed with (Somchit et al .2004) have observed severe inflammation, hepatocellular necrosis, severe hepatic necrosis and bile duct hyperplasia in rats treated with itraconazole with significant increase in ALP and ALT activities. Such suggestion was supported by (Sozen et al., 2014) who explained that may be due to reactive oxygen species (ROS) production which interact with biological macromolecules leading to enzyme inactivation, DNA damage and initiating lipid peroxidation. This opinion was suggested also by (Işlekel et al 1999) who reported that ROS causes cellular damage through oxidation of membrane lipids and essential cellular proteins with release of proteolytic lysosomal enzymes and mitochondrial matrix enzymes.

In this study, low levels of oxidative stress markers, SOD, CAT and GSH in the liver tissues of rats with the increased concentration of MDA were suggestive of lipid peroxidation and tissue damage. These findings were supported by (Sozen et al., 2014) who observed that itraconazole resulted in significant elevation in myeloperoxidase and nitric oxide levels with significant reduction in the antioxidant activity of superoxide dismutase and GSH-peroxidase. The increased oxidative stress in the liver is thought to play a major role in liver injury. The mechanism underlying the hepatotoxicity of itraconazole remains unclear. According to (Somchit et al., 2009) who were suggested that cytochrome P450 may play a key role in preventing the liver toxicity of certain azoles, especially itraconazole. According to (Francois et al., 2006) the azole antifungal resulted in ROS generation through inhibition of peroxidase and catalase which were involved in 
breakdown of peroxide radicals and hydrogen peroxide. The oxidative stress damage caused by itraconazole is consistent with previous studies using different antifungals (Liu et al., 2002) and (Rodriguez and Buckholz., 2003).

One of the major adverse effects of itraconazole is hepatotoxicity which is the major complication of its administration. Thus, amelioration of hepatotoxicity would enhance its clinical use. In this experiment pre-treatment with CoQ10 significantly reduced vacuolation which were most probably lipid vacuoles and attenuated itraconazole induced hepatotoxicity. This result goes in hand with (Jimenez-Santos et al., 2014) who found that CoQ10 supplementation reduce the hepatic oxidative stress and improves metabolic parameters and liver function in hypercholesterolemic rats which may be due to the hypolipidemic activity of CoQ10.These results were in harmony with (Chen et al. 2019) who showed that CoQ10 regulates the hepatic lipid metabolism to inhibit the abnormal accumulation of lipids in the liver cells. In addition (Esfahani et al. 2013) who reported improvement in AST and ALT concentrations and improvement of portal inflammation and hepatocellular liver necrosis in thioacetamide-induced liver damage in rats. CoQ10 possesses hypolipidemic effects in rats supplemented with high cholesterol diet in a study by (Al-Attar 2010) who found that CoQ10 low down the values of lipid profile levels which might be due to inhibition of hepatic cholesterol formation with subsequent redistribution and utilization of cholesterol from plasma to the liver through the cholesterol metabolizing enzyme systems in the liver.
In the present study with pre-treatment with CoQ10 a significant decrease in the area percentage of PCNA positive hepatocytes was noticed in comparison to itraconazole group. This might be explained by (Giboney., 2005) who reported that CoQ10 has anti-oxidant effect, preventing the oxidation of proteins, DNA, and lipids.

Regarding the CoQ10 and itraconazole treated group, mitochondrial swelling was alleviated. Such improvement might be due to the possible protective effect of CoQ10. Lenaz et al., (2006) mentioned that CoQ10 is endogenous lipid soluble compounds that act as a diffusible electron carrier in the mitochondrial respiratory chain. Moreover, CoQ10 in humans was known for its key role in mitochondrial bioenergetics (Silver et al., 2004). CoQ10 has been found to be a key component in mitochondrial function (Deichmann et al., 2010). Localized in the inner mitochondrial membrane, it facilitates electron transfer in the generation of adenosine triphosphate (ATP) (Siciliano et al., 2007).

In this study it is evidenced elevation in the activities of SOD and GSH in the liver tissue by CoQ10. Such improvement might be due to the possible protective effect of CoQ10. This hypothesis was so far supported by the reports, as Esfahani et al. (2013) and Emam et al. (2016) who found that CoQ10 resulted in a significant reduction in the serum ALT \& AST and liver MDA level, it also restored liver GSH content in Lipopolysaccharides induced liver injury. Furthermore, in human (Lee et al., 2012) described that COQ10 significantly increased serum catalase and superoxide dismutase activity 
and decrease in MDA concentration in patients with coronary artery disease.

This protective effect might be related to antioxidant properties of COQ10 and its ability of to neutralize the increase in the free radicals cause by itraconazole. These results agreed with earlier findings of (Shekelle., 2003), who mentioned that the antioxidant capacity of CoQ10 was much higher than vitamin $\mathrm{C}$ or vitamin $\mathrm{E}$ in human studies. This finding is explained by (Matés.,2000) who stated that excess reactive oxygen species ROS are eliminated by antioxidant enzymes, which are represented by SOD, GPX and CAT in the body. SOD directly changes superoxide anion to hydrogen peroxide thereafter both GPX and CAT, the two main enzymes, are required in the detoxification of $\mathrm{H} 2 \mathrm{O} 2$ in a cellular antioxidant defense system.

\section{CONCLUSION}

Our study showed that although itraconazole is well tolerated, clinicians should be alert that prolonged oral itraconazole administration is hepatotoxic. Patients who required treatment with this drug for long periods should be under periodic liver enzymes monitoring. Results of the present study suggests that pre-treatment with COQ10 attenuated the development of itraconazole -induced hepatotoxicity.

Declaration of conflicts of interest: No conflicts of interest.

\section{Funding details:}

This research did not receive any specific grant from funding agencies in the public, commercial, or not-for-profit sectors.
Acknowledgements: The authors like to express their deep gratitude to electron microscope unit -Faculty of science, Ain Shams University and Pathology Department, Faculty of Dentist, Cairo University for their cordial help and work on the histological and immunohistochemical study of this work.

\section{REFERENCES}

1. Acosta MJ, Vazquez FL, Desbats MA, Cerqua, C, Zordan R, Trevisson E, and Salviati L. (2016): Coenzyme Q biosynthesis in health and disease. Biochim. Biophys. Acta, 1857(8):1079-1085.

2. Adil M, Kandhare AD, Visnagri A, and Bodhankar SL. (2015): Naringin ameliorates sodium arsenite-induced renal and hepatic toxicity in rats: decisive role of KIM-1, Caspase-3, TGF- $\beta$, and TNF- $\alpha$. Ren. Fail., 37(8):1396-1407.

3. Al-Attar AM. (2010): Hypolipidemic effects of coenzyme Q10 in experimentally induced hypercholesterolemic model in female rats. Am. J. Pharmacol. Toxicol., 5(1):14-23.

4. Bellmann R. and Smuszkiewic P. (2017): Pharmacokinetics of antifungal drugs: practical implications for optimized treatment of patients. Infection, 45(6):737-779.

5. Chen K, Chen X, Xue H, Zhang P, Fang W, Chen X., and Ling W. (2019): Coenzyme Q10 attenuates high-fat diet-induced nonalcoholic fatty liver disease through activation of the AMPK Pathway. Food. Funct., 10(2):814-823.

6. Cheung P, Zhan Q, Zhang YO, Bai GR, Lin MC, Chan B, Fong CC, Shi L, Shi YF, Chun J, Kung HF and Yang M. (2006): Effect of WeiJia on carbon tetrachloride induced chronic liver injury. World. J. Gastroenterol., 12(12):1912-1917.

7. Da Silva MC, Mendonça LM, Venancio VP, Bianchi ML and Antunes LM. (2013): Coenzyme Q10 protects Pc12 cells from cisplatin-induced DNA damage and neurotoxicity. Neurotoxicology, 36:10-16. 
8. Deichmann $R$, Lavie $C$ and Andrews $S$. (2010): Coenzyme Q10 and statin-induced mitochondrial dysfunction. Ochsner. J.; 10(1):16-21.

9. Ellman, G.L (1959): Tissue sulfhydryl groups. Arch. Biochem. Biophys., 82:70-77.

10. Emam A M, Georgy G S, Shaker O G, Fawzy $H$ M, and Zaki H F. (2016): Protective effects of alpha-lipoic acid and coenzyme Q10 on lipopolysaccharide-induced liver injury in rats. Pharm Lett., 8(19):176182.

11. Esfahani SA, Esmaeilzadeh E, Bagheri F, Emami Y and Farjam M. (2013): The effect of co-enzyme Q10 on acute liver damage in rats, a biochemical and pathological study. Hepat. Mon., 13(8): e13685.

12. Francois IE, Cammue, B, Borgers $M$, Ausma J, Dispersyn G D and Thevissen K. (2006): Azoles: mode of antifungal action and resistance development. Effect of miconazole on endogenous reactive oxygen species production in candida albicans. Anti-infective Agents in Medicinal Chemistry, 5(1):3-13.

13. Giboney PT (2005): Mildly elevated liver transaminase levels in the asymptomatic patient. Am. Fam. Physician, 71(6):11051110 .

14. Girois SB, Chapuis F, Decullier $E$ and Revol B G (2006): Adverse effects of antifungal therapies in invasive fungal infections: review and meta-analysis. Eur. J. Clin. Microbiol. Infect. Dis.; 25:138-149.

15. Glauret, A. and Lewis, A (1998): Biological specimen preparation for transmission electron microscope, 1st ed., vol. 17. Pbl .Portland Press, London.

16. Hassan IM, Sammour BMA and El-Saie IA (1988): Histological and histochemical studies on the liver of albino rats Under the Effect of Ketoconazole (Nizoral). Egypt. J. Histol., 11:51-59.

17. Işlekel H, Işlekel S, Güner $G$ and Ozdamar N (1999): Evaluation of lipid peroxidation, cathepsin $\mathrm{L}$ and acid phosphatase activities in experimental brain ischemia-reperfusion. Brain. Res; 843(1-2):18-24,
18. Jimenez-Santos MA, Juarez-Rojop I E, Tovilla-Zarate CA, Espinosa-García M T, Juárez-Oropeza $M$ A, Ramón-Frías $T$, Bermúdez-Ocaña DY and Díaz-Zagoya JC (2014): Coenzyme Q10 supplementation improves metabolic parameters, liver function and mitochondrial respiration in rats with high doses of atorvastatin and a cholesterol-rich diet. Lipids. Health Dis, 13:22,

19. Kemeir MEA, (2014): Hepatotoxic effect of itraconazole in experimental rats. Am. J. Animal.Vet. Sci., 9:46-52.

20. Kumar V, Abbas A and Fausto N (2004): Robbins, and Cotran Pathologic Basis of Disease. 7th Ed., Elsevier Saunders, Philadelphia,7: 632-666.

21. Lee BJ, Huang YC, Chen SJ and Lin PT (2012): Coenzyme Q10 supplementation reduces oxidative stress and increases antioxidant enzyme activity in patients with coronary artery disease. Nutrition, 28(3):250255.

22. Lenaz G, Baracca A, Fato R, Genova ML and Solaini G (2006): Mitochondrial Complex I: Structure, Function, and Implications in Neurodegeneration. Ital. J. Biochem., 55(3-4):232-253.

23. Liu CF, Lin CC, Ng LT and Lin SC (2002): Hepatoprotective and therapeutic effects of tetra methylpyrazine on acute econazoleinduced liver injury. Planta Med., 68(6):510514.

24. Matés JM (2000): Effects of antioxidant enzymes in the molecular control of reactive oxygen species toxicology. Toxicology, 153(1-3): 83-104.

25. Morales-González JA, Jiménez-García LF, Guitérrez-Salinas J, Sepúlveda J, LeijaSalas A and Hernández-Muñoz R (2001): Effects of Ethanol Administration on Hepatocellular Ultrastructure of Regenerating Liver Induced by Partial Hepatectomy. Dig. Dis. Sci., 46:360-369.

26. Ochei JO and Kolhatkar AA (2008): Medical laboratory science: theory and practice. Tata McGraw-Hill Publishing Company Limited, New York pp. 637-745. 
27. Ohkawa H, Ohishi N, and Yagi K (1979): Assay for lipid peroxides in animal tissues by thiobarbituric acid reaction. Anal. Biochem., 95(2):351-358.

28. Rafique M, Shaikh AA and Syed NS (2010): Morphometric study of ketoconazole treated liver in albino rats. Pak. J. Pharmacol., 27(1):11-17.

29. Rodriguez RJ and Buckholz CJ (2003): Hepatotoxicity of ketoconazole in spraguedawley rats: glutathione depletion, favincontaining monooxygenases-mediated bioactivation and hepatic covalent binding. Xenobiotica, 33(4):429-441.

30. Rubin E (2001): Essential pathology, 3rd ed. Pbl. Lippincott Williams \& Wilkins,

31. Russmann S, Kullak-Ublick GA and Grattagliano I (2009): Current concepts of mechanisms in drug-induced hepatotoxicity. Curr. Med. Chem., 16(23):3041-3053.

32. Shekelle P, Morton $S$ and Hardy ML (2003): Effect of supplemental antioxidants vitamin $\mathrm{C}$, vitamin $\mathrm{E}$, and coenzyme Q10 for the prevention and treatment of cardiovascular disease. Evid. Rep. Technol. Assess. (Summ)., (83):1-3

33. Siciliano G, Volpi L, Piazza S, Ricci G, Mancuso $M$ and Murri L (2007): Functional diagnostics in mitochondrial diseases. Biosci Rep., 27(1-3):53-67.

34. Silver MA, Langsjoen PH, Szabo S, Patil H and Zelinger A (2004): Effect of atorvastatin on left ventricular diastolic function and ability of coenzyme Q10 to reverse that dysfunction. Am. J. Cardiol., 94(10):13061310 .

35. Simmons $M$ and Brick J (1970): Collection of Blood from Orbital Sinus in the Laboratory
Mouse: Selection Management.1st ed. Pbl. Prentice- Hall, New Jersey, pp.150 -162.

36. Somchit N, Ngee CS, Yaakob A, Ahmad Z and Zakaria ZA. (2009): Effects of cytochrome $\mathrm{P} 450$ inhibitors on itraconazole and fuconazole induced cytotoxicity in hepatocytes. J. Toxicol., :912320.

37. Somchit N, Norshahida AR, Hasiah AH, Zuraini A, Sulaiman M R and Noordin M $M$ (2004): Hepatotoxicity induced by antifungal drugs itraconazole and fluconazole in rats: A Comparative in vivo study. Hum. Exp. Toxicol., 23(11):519-525.

38. Sozen H Celik OI, Cetin ES and Yilmaz N (2015): Evaluation of the protective effect of silibinin in rats with liver damage caused by itraconazole. Cell Biochem. Biophys, 71(2):1215-1223.

39. Talwalkar JA Soetikno RE, Carr-Locke DL and Berg CL (1999): Severe cholestasis related to itraconazole for the treatment of onychomycosis. Am. J. Gastroenterol., 94(12):3632-3623.

40. Tverdek FP, Kofteridis D, and Kontoyiannis DP (2016): Antifungal agents and liver toxicity: a complex interaction. Expert. Rev. Anti. Infect. Ther., 14(8):765776.

41. Wilson I and Gamble $M$ (2002): The hematoxylins and eosins. In: Bancroft JD, Gamble M, Theory and practice of histological techniques, 5th ed. Churchill Livingston, London: 125-138. 
تأثير الإيتر اكونازول على كبد الجرذان البيضاء البالغة من

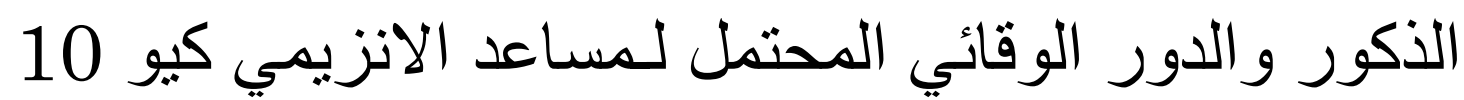
(دراسة هيستولوجيا وكيمياء المناعية و البيوكيميائية)

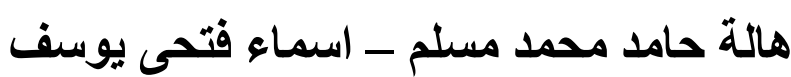

قسمي التشريح والاجنة والفسيولوجيا ـ كلية الطب ( بنات ) ) - جامعة الازهر

\section{E-mail: halahamed1000@gmail.com}

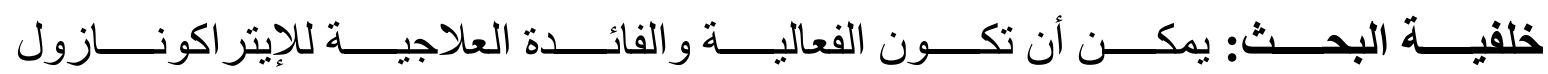
كدو اء مضاد للفطريات محدودة سريريًا بسبب حدوث السمية الكبدية.

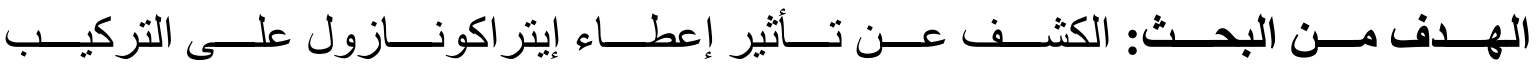

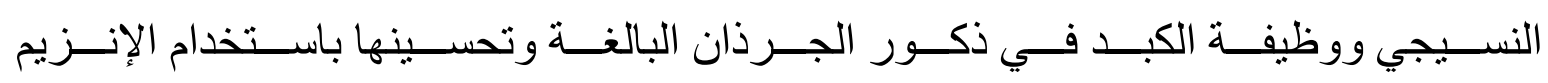
المساعد (COQ 10). (2) (10).

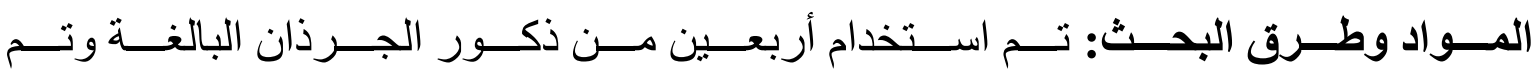

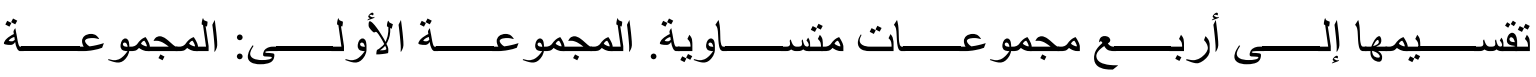

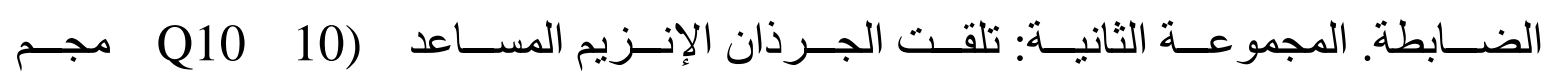

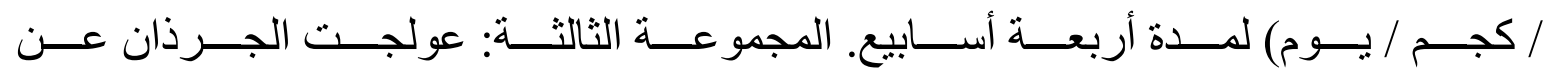

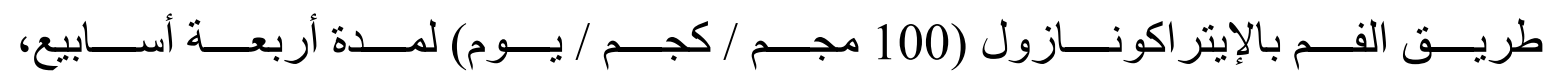

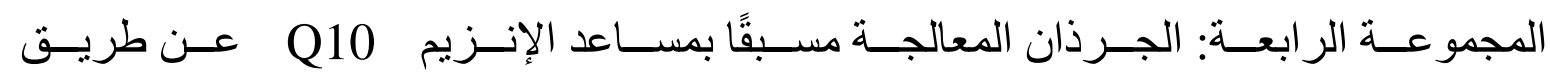

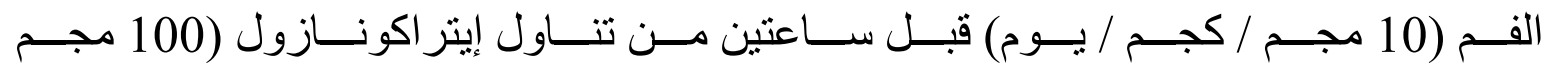

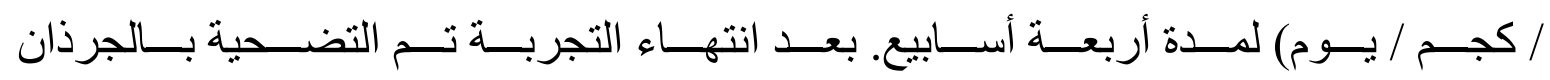

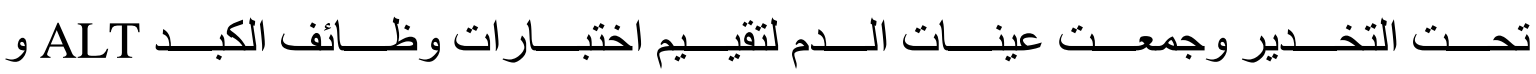
ALP و AST GSH g $, \mathrm{CAT}, \mathrm{SOD}$ MDA

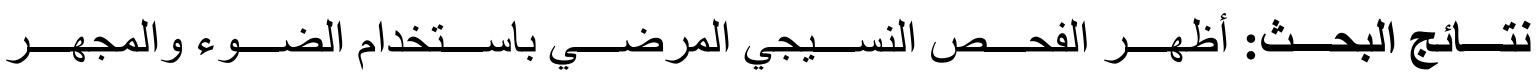

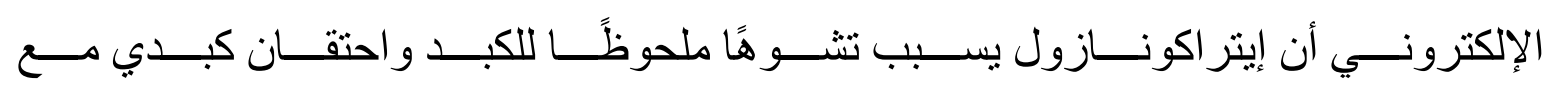




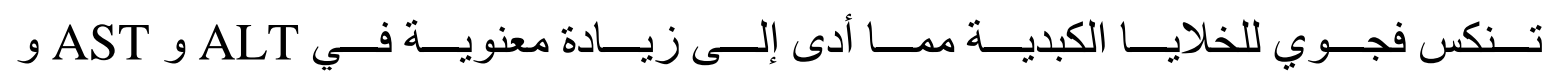

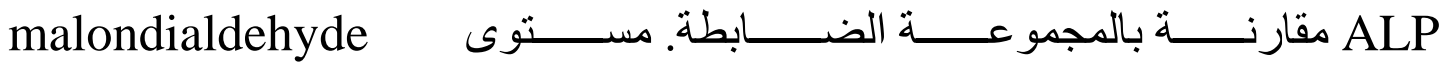

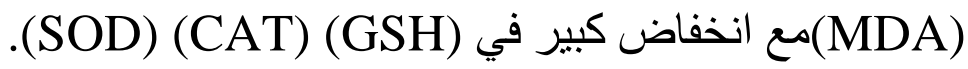

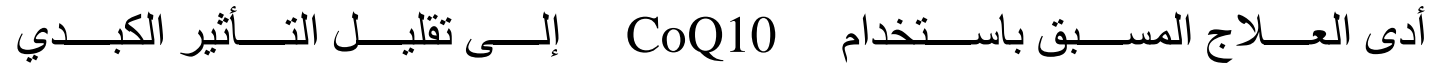

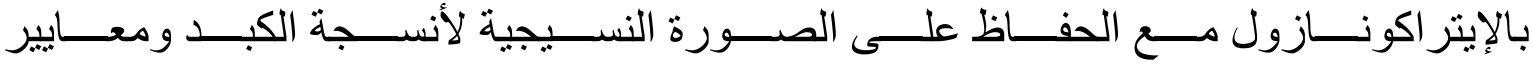
وظائف الكبد و المؤشر ات الحيوية للإجهاد التأكسدي.

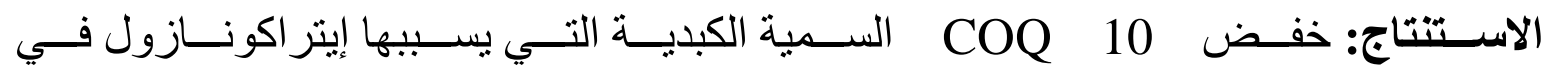

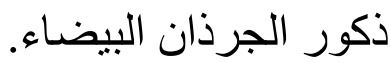
الكلمات الدالة: مضادات الأكسدة، إيتر اكونازول، الكبد، الفئران، السمية. 